\title{
A psycho-philosophical view on the 'conceptualisation' of psychological measure development
}

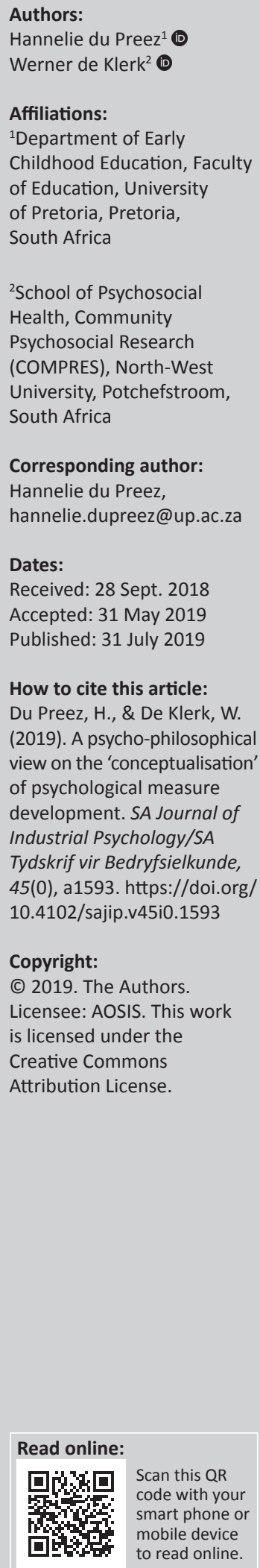

Orientation: When researchers' understanding and application of 'conceptualisation' can allude to nearly anything, it loses its philosophical purpose and stature. Negating the philosophical meaning of the term 'conceptualisation', because it appears obvious, will result in research inquiries becoming ambiguous and ideologically diminished. Paradigms and theoretical frameworks are rooted in philosophical principles, yet researchers often 'conceptualise' and conduct inquiries without understanding the foundation of their applied scientific methods.

Research purpose: The historicity of psychological measurement development depicts a fusion of transdisciplinary knowledge systems and the stature of scientific methods is comprehensive. Yet the philosophical lenses through which researchers 'conceptualise' their measure to understand psychological behaviour are not as clear.

Motivation for the study: Contemporary psychometric literature postulates the 'conceptualisation phase' as a mere point of departure to develop a psychological measure, whereas philosophical literature depicts 'conceptualisation' as the mainstay of any research inquiry.

Research approach/design and method: A qualitative design was used with the conceptual analysis of terminology as approach. Textual or typographical psychometric and psychological literature was purposively sampled and inductively and deductively analysed, using the philosophical framework of Van der Walt and Potgieter.

Main findings: The definition of the 'conceptualisation phase' is principally characterised as the scientific method to measure the scientific reality, while the integral human component, represented by the measure developer, is overlooked.

Practical/managerial implications: Insights derived can enthuse future dialogues on the purpose and importance of the conceptualisation phase in the development of psychological measures.

Contribution/value-add: A potential delineation of what the 'conceptualisation phase' should encapsulate is proposed.

Keywords: Conceptual analysis; conceptualisation; conceptualisation phase; psychophilosophical viewpoints; psychological measure development.

\section{Introduction}

Psychological measures, or psychometric tools, typically constitute a process-orientated action to objectively and systematically gather information about aspect(s) of a person's psychological behaviour or being, whereupon inferences are drawn to inform decisions and/or make recommendations (Anastasi \& Urbina, 1997; Murphy \& Davidshofer, 2014; Ryan, Lopez, \& Sumerall, 2001; Schweizer \& DiStefano, 2016). In brief, a psychological measure characterises a clearly designed map of constructs or latent traits (scientific reality) and the measurement (scientific method) thereof (Finkelstein, 2003; Michell, 1997).

This generic definition is evidence of important fundamentals when developing a psychological measure; however, what the conceptualisation phase in measure development pertains to is consequently not as clear as assumed. The fundamentals of the definitions of psychological measure indicate rigorous experimentation and mathematisation to measure constructs. However, the measure developer's own philosophical lens or interpretation of the scientific method and the scientific reality is not explicitly accounted for (Borsboom, 2005, 2006; Maul, Torres Irribarra, \& Wilson, 2016; Michell, 1997). A serious social scientist, scholar or researcher, also 
implying a measure developer, characterises someone who carefully considers their philosophical positioning when conceptualising before operationalising their actions (Comte-Sponville, 2005, Harris, 2010). Social science is a branch of the philosophy of science (Delanty \& Strydom, 2010), and the practice of measurement has philosophical implications (Michell, 2005). Therefore, the body of scholarship of social sciences, psychology and philosophy are integrated, not dichotomous, and for this article labelled a psycho-philosophical view.

Supportive literature indicated that terminology in social sciences and psychology is commonly overlooked, not studied, not questioned, and frequently accepted as being self-explanatory, obvious or apparent (Cocchiarella, 2007; Petocz \& Newbery, 2010). Words, concepts, terms and symbols are the only mediums available for conveying meaning, and such terminology gives voice to serious measure developers to structure their thoughts and determine their prediction in language. Therefore, clarifying concepts and terminology, disclosing conceptual anomalies in theories and models, questioning unsound assumptions and arguments and evaluating the reliability of procedural methods are much needed (Borsboom, 2006; Petocz \& Newbery, 2010).

Conceptualisation, as one of seven phases (see Figure 1), is precariously open for unguided interpretation, faces the risk of detaching from its precise meaning and understanding, and might become vague and manifold (Cocchiarella, 2007; Hutto, 2013). Seeing that the meaning of the 'conceptualisation phase' is not always obvious, it is sometimes confused with or seen as part of the operationalisation phase(s). This suggests that the serious measure developer's insinuations, inclinations, assumptions and/or biases influence his or her understanding of the scientific reality and the scientific method; the more reason to delineate the conceptualisation phase. As soon as language eludes signs, index, description or register, philosophical scrutiny becomes necessary (Hutto, 2013; Margolis \& Laurence, 2007).

The conceptual and methodological silences in the body of scholarship inspired us to formulate and answer the research question: What is the psycho-philosophical meaning of 'conceptualisation' as the first phase during the development of a psychological measurement? We were set to explore the existing body of scholarship pertaining to the 'conceptualisation phase' of psychological measure development. We critiqued the sampled textual sources and identified a lacuna in the delineation of the conceptualisation phase by using a philosophical a priori framework. We found that 'conceptualising' a psychological measure is an iterative, continuous and intentional process of abstracting, simplifying and categorising. It is a conceptual mapping of the ontological scientific reality, its epistemological scientific method, and the anthropological and axiological scientific understanding of human behaviour and being, as a relational system.

\section{Literature review}

Research endeavours in psychometrics show evidence of and support for measure development, utilisation and advancement in the pursuit of esteemed psychometric modelling (Borsboom, 2005, 2006; Goldstein \& Beers, 2004). Scientific knowledge systems, and therefore psychological measure frameworks, comprise statements and approximations about reality (the ontological-epistemological criterion) that are in accordance with the evidence that alludes to the application of rigorous techniques and methods (the objectivity criterion), which are scrutinised and accepted or rejected by a scientific community (the rational criterion) (Babbie \& Mouton, 2001). To contextualise each of these aspects that constitute a scientific knowledge system, we allude to the historicity of psychological measurement development, conceptualisation, the nature of a psychological measure and the development thereof against the backdrop of a psycho-philosophical context.

\section{The historicity of psychological measure development}

The origin of measurement can be traced back to the physical sciences (Finkelstein, 2003). Measurement has since been applied in diverse inter- and trans-disciplinary fields of study, and has achieved prominence in psychology and the social sciences (Humphry, 2013; Jones \& Thissen, 2006). The historicity of measurement signals four major physical science and mathematical eras that contributed to and served as an important impetus in the establishment of psychometrics as a disciplinary field, namely, the syncopated era (500 BC1000 AD); the Middle Ages or symbolic era (1000-1500 AD);

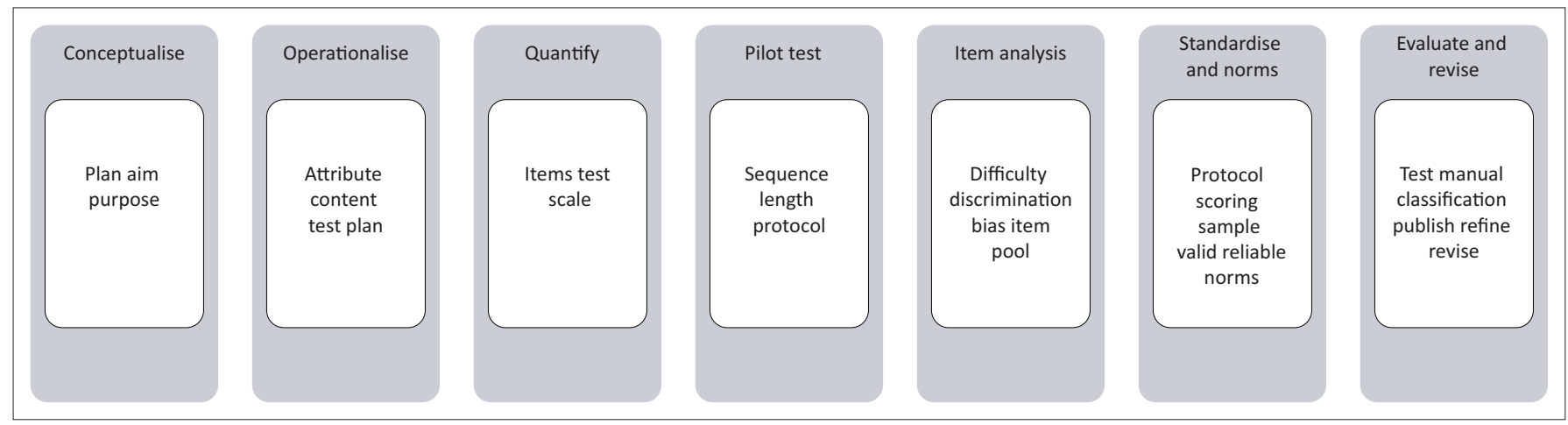

FIGURE 1: Outline of phases involved in psychological measure development. 
the modern era (1500-1900 AD) and, finally, the contemporary era (1900 AD-present). Each of these eras, and their respective renowned scholars, revolutionised how the foundations of measurement tools were invented, practised and revised, drawing on both philosophical and mathematical viewpoints (Finkelstein, 2003).

The innovative works of astronomer, physicist, engineer, philosopher and mathematician Galileo contributed to the nexus of the theory-praxis dichotomy, as he quantified observations of the physical world through mathematics (Finkelstein, 2003). A trajectory of continuous discoveries charted the quest for closing the theory-praxis gap by quantifying human's psychological behaviour and being. A succinct trajectory of some revolutionary works is: (1) Newton and Maxwell's mathematical theories how to denote the physical world; (2) psycho-physicist Helmholtz's contribution to a modern theory of measurement; (3) philosopher, physicist and experimental psychologist Fechner, who is the founder of psychophysics; (4) Campbell's work on physical quantities for empirical operation; (5) the nature of measurement in psychology by Stevens, and philosophically analysed by Ellis; (6) the institution of scholarly journals (Psychometrika and Psychometric Methods) and the Psychometric Society by psycho-physicist Thurstone and psychologist Guildford; and (7) the leap forward in proposing the representational theory of measurement by Tarski, Suppes, Zinnes, Luce and Krantz, to name a few (Finkelstein, 2003; Humphry, 2013; Jones \& Thissen, 2006; Michell, 1997).

The historicity of psychometrics, firstly, signalled the importance of fusing fields of study and their knowledge systems and, secondly, indicated how philosophy has shed light on a scientific hiatus, and vice versa. Observing and understanding human psychological behaviour is not only a philosophical, scientific or a mathematical phenomenon. Rather, scholars from these distinct fields of study recognised the importance of establishing an intellectual cohort to advance the scientific measurement of a scientific reality. In other words, the origins of psychometrics herald important transitions and revolutions, such as hybridising transand cross-disciplinary fields of knowledge, incorporating innovative views on reality and joining scholarly communities (Borsboom, 2006; Finkelstein, 2003; Jones \& Thissen, 2006).

As with any discipline, psychometrics also has manifold measurement models and theories, which are based on works of particular, serious scientists, operating from very specific paradigmatic orientations. For example, the test for individual differences is associated with Gauss, Bessel, Galton and Cattell, while factor analysis was pioneered by Spearman, Thomson, Binet, Goddard and Terman (Humphry, 2013; Jones \& Thissen, 2006). In addition to these theories is the Rasch model, based on the mathematical theory of item response theory, and the psychological measurement and multidimensional scaling, as influenced by Thurstone, Luce, Tukey, Guttman, Tucker and Messick, among others (Humphry, 2013; Jones \& Thissen, 2006). Scrutinising the underlying theoretical premises of each of the aforementioned scholars is not the focus of the article; however, it is important that a serious measure developer should establish his or her theoretical framework when conceptualising a psychological measure. The historicity of psychometrics contextualises and informs our psycho-philosophical understanding of the importance of conceptualisation.

\section{Conceptualisation}

From a philosophical point of view, conceptualisation characterises a scholar's act of going through an iterative, continuous and intentional process to abstract, simplify and categorise his or her impressions, experiences or perceptions of a phenomenon or reality, to give meaning, purpose or expression through clear and descriptive language (Babbie \& Mouton, 2001; De Vos \& Strydom, 2011). This philosophical explication moots the possibility for the serious measure developer to map 'an empirical relational system into a welldefined theory in a mathematical language' (Finkelstein, 2003, p. 44). Therefore, conceptualisation is crucial to understand the history, philosophy and purpose of the intended measure, which represents its nature.

\section{Nature of psychological measurement}

The nature of a psychological measure is the experimentation and mathematisation of the scientific reality through a scientific method (Michell, 1997, 2005). Evidently, the majority of working definitions draw on science- and mathematicsrelated terminology, for example, 'process-orientated', 'systematic', 'scientific', 'standardise', 'norms', 'categories', 'scales' and, of course, 'quantify'. Maul (2013) and Maul et al. (2016), on the other hand, suggest that any measure has a philosophically infused foundation, which is not accounted for in most working definitions.

In light of the two perspectives on the nature of a psychological measure, it seems that consensus on the delineation of a psychological measure has not been reached, because the merit of the scientific reality, the scientific method, as well as philosophically infused provisions, are not evident in all working definitions. To better understand the complex nature of a psychological measure, firstly, warrants a better understanding of how a psychological measure is developed step-by-step (or phase-by-phase) and, secondly, realising the importance of psycho-philosophical contexts.

\section{Psychological measure development}

Acknowledged frameworks stipulate specific stages, phases or steps when developing a psychological measure (see Figure 1). Although a universally accepted exact, sequential and descriptive model has not yet been agreed upon, we have scrutinised the body of scholarship and developed a probable depiction, or side-by-side illustration, which represents the acceptable and sequential phases and their tasks that are evident in the process of developing a psychological measure (Chadha, 2009, pp. 87-90; Coaley, 2014, pp. 52-53; Cohen \& Swerdlik, 2009, pp. 245-252; Foxcroft \& Roodt, 2013, 
pp. 70-74; Kingston, Scheuring, \& Kramer, 2013, pp. 165-182; Moerdyk, 2009, pp. 27-28; Murphy \& Davidshofer, 2014, pp. 227-238; Ryan et al., 2001, pp. 1-4; Wright, 1999, pp. 65-101).

Figure 1 is a preliminary representation of the scientific reality and the scientific method of a philosophical measure; however, the philosophically infused provisions are not obvious, which call for a psycho-philosophical context.

\section{Psycho-philosophical context}

Philosophy has always been concerned with the fundamental question of what it means to be human and its corollaries of what truth is and how we can know it. The question that Galileo asked, 'What has philosophy got to do with measuring?' (Drake, 1999, p. 266) and its teased obverse, 'What has measuring got to do with philosophy?' (Michell, 2005 , p. 285) indicate a historical dichotomy - a division where measure developers have to choose between science and philosophy, whereas the advancement of a measurement necessitates unifying science and philosophy (Maul et al., 2016; Michell, 1997, 2005). According to Oono (2012, p. v), the investigation of realities to convey clarity and precise meaning is, indeed, important research, because researchers ought to make 'intuitively grasped concepts clear'.

A psycho-philosophical lens can facilitate a conceptual tribunal and collaborative ingenuity; it can assure that the psychological measure is conceptually clear, ethical towards humankind, meaningful and relevant through proper conceptualisation (Hacker, 2013). 'The license that philosophy possesses to intervene in scientific debates is a critical one, but the licit criticism is not empirical. It is purely conceptual' (Hacker, 2013, p. 20). In this context, we adopted the notion stressed by Maul $(2013)$ and Michell $(1997,2005)$ to include philosophical principles in the working definition and potentially breaking away from common practice, where synonyms and word substitutions are used, which misconstrues the intent and meaning of conceptualisation.

\section{Research design \\ Concept analysis of terminology}

Qualitative social research endeavours ordinarily serve diverse purposes, among which are exploring, describing and explaining scientific knowledge systems, and clarifying concepts and terminology (Babbie \& Mouton, 2001). Concept analysis is a process to guide the exploration of a term that is new, ambiguous and/or underdeveloped (Hughes \& Duffy, 2018). Although concept analysis requires the systematic investigation of the characteristics or attributes of a concept to clarify its meaning (Hughes \& Duffy, 2018; Nuopponen, 2010a, 2010b, 2011), it should not be confused with a systematic review or meta-analysis. A systematic review summarises key quantitative and qualitative scientific contributions to a field, while meta-analysis offers a statistical procedure to fuse findings to obtain overall reliability (Tranfield, Denyer, \& Smart, 2003). The rationale for using

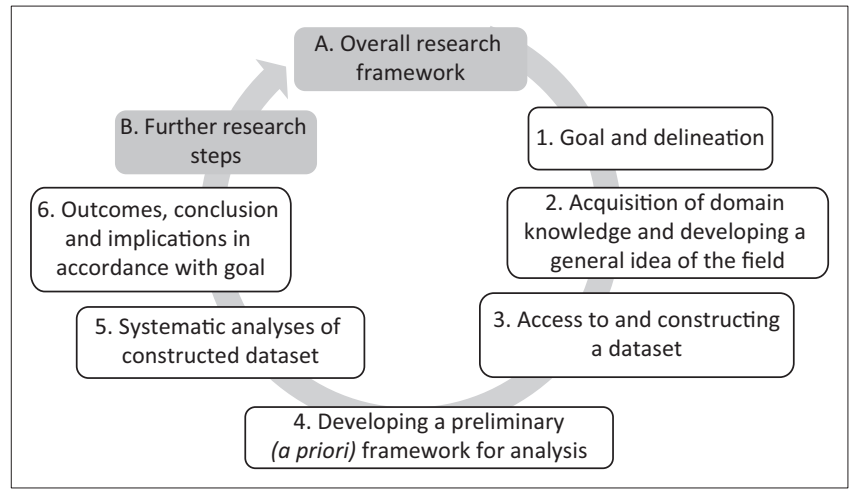

Source: Adapted from Nuopponen, A. (2010b). Methods of concept analysis - Towards systematic concept analysis. Part 2 of 3. LSP Journal, 1(2), 6 .

FIGURE 2: Outline of the concept analysis of terminology.

concept analysis is to clarify and delineate terminology that are open to subjectivity, individual interpretation and multiple truths (Hughes \& Duffy, 2018) We wanted to explore the delineation of the 'conceptualisation phase' according to psychometric as psychological (social science and psychology) textual sources; and elaborate on its meaning by interpreting it through a philosophical lens. We derived a possible delineation for the 'conceptualisation phase' and further dialogues on this delineation beckon. Different models can be utilised to conduct conceptual analysis (Hughes \& Duffy, 2018), but for this inquiry we drew on Nuopponen's (2010a, 2010b, 2011) six generic phases, as depicted in Figure 2.

In the first two phases, the purpose, scope and knowledge domains for the analysis of the term 'conceptualisation' are delineated. Utilising this particular research approach indicates that to clarify or give meaning to a term, that cannot be sufficiently addressed by a mere literature review, requires a research investigation.

Phase three consists of identifying, attaining and constructing a textual or typographical dataset, from which an informed understanding about the discipline is formed (Nuopponen, 2010b). Our study is categorised as an empirical study in which we utilised existing typographical or textual sources to construct a particular and restricted textual dataset, which we then analysed. The integral and central part of our methodology comprised continuously scanning, scoping, gathering and selecting the most suitable textual sources for analysis and interpretation in a systematic and purposive manner (Babbie \& Mouton, 2001). We collaborated with an information specialist to sample scholarly textbooks, using specific search terminology to locate either virtual (computerised) or physical (non-computerised) literature. This search was guided by establishing inclusion and exclusion criteria. The first inclusion criterion was that the content of the source should match the predetermined terminology or keywords (e.g. 'conceptualise' and/or 'conceptualise phase' and 'plan? phase' in 'measure?', and/ or 'assess?', and/or 'test' in 'psychometric', and/or 'psychological' in and/or 'measure?', and/or 'assess?', and/ or 'test'). Secondly, the textual sources had to represent the works of renowned scholars within the field of psychometrics 
and psychology; a body of scholarship on how to objectively and systematically measure psychological behaviour or being. Thirdly, each source should be accessible in its full electronic or printed format through an official and authorised library. Lastly, the selection of sources should represent both international and national scholars and be written in or translated into English. In relation to the exclusion criteria, we firstly discarded texts where the psychological measurement development was not located in psychology or psychometrics. Secondly, texts elucidating phases other than conceptualisation and/or planning or accounts of actual measuring or assessing of specific psychological constructs were rejected. Lastly, texts published in a language other than English were also not selected. We identified and scrutinised nine existing or typographical sources because they complied with all the inclusion and exclusion criteria and fit the purpose of this inquiry.

In phase four we identified a philosophical framework, because all research, including measure development, should be clarified and legitimised by the philosophical framework (Harris, 2010; Van der Walt \& Potgieter, 2012). This particular a priori framework consisted of four philosophically inspired pre-scientific provisions, as founded in the work of Van der Walt and Potgieter (2012), and guided our thinking and reasoning about 'conceptualisation' during analysis and interpretation. The four philosophical pre-conditions and justifications provide conceptual clarity and guide a researcher's thinking and decisions about the scientific reality and the scientific method which influence the quality of the outcome or product or finding. The importance of a framework to explain the construct (scientific reality) is also alluded by leading Rasch measurement theorists Bond and Fox (2015) and Boone, Staver and Yale (2014). A serious measure developer should focus firstly on theoretical premises underlying the construct (scientific reality) and thereafter on the quantitative analysis (scientific method). Conceptualising and refining a psychological measure should primarily be carried out for construct representation; in other words, the data should fit the philosophical framework (Bond \& Fox, 2015; Boone et al., 2014).

The first provision is integrated personality positioning, which is the intentional choice of a researcher, as a holistic individual being, to unify or connect with his or her choice of research inquiry and ideological preferences. Furthermore, it is expected that a researcher should demonstrate qualities such as integrity, moral reflectiveness, authenticity, trustworthiness and dedication to serve others when conducting research. The second provision, namely transcendental positioning, denotes the intentional and theoretical deductions that a researcher cherishes about the research topic, such as his or her own assumptions, values, predispositions and intuitive thinking. Although the latter account could be considered as being an 'opinion', rather than a scientific fact, it remains likely that a researcher's underlying ontology will ultimately guide his or her research conduct pertaining to the choice of epistemology, cosmology, anthropology and methodology. The third provision, teleological positioning, acknowledges the importance of envisioning the outcome or reflecting on the purpose of a research inquiry and, therefore, what the researcher aims to attain when developing a measure. The intentional reflection on the outcome of the measure should resonate with his or her integrated and transcendental orientation and serve not only as an encouraging driving force to develop a measure but also to warrant a trustworthy and authentic outcome that mirrors quality and excellence in every aspect of the word. Lastly, a nomothetic positioning refers to a researcher's informed decision to consider an audience whom the outcome can affect and to whom it can contribute. Given the importance of establishing a community of scholars, such an audience can be sampled on the premises of ontological, epistemological and anthropological choices.

Commencing phase five, we were cautious (Guarino, 1995; Margolis \& Laurence, 2007) not to cherish an all-confounding illusion to finally define the 'conceptualisation phase'. Rather, we deductively and inductively analysed, compared and interpreted the dataset in order for us to develop a clearer understanding of the terminology and to linguistically express our finding and delineate this phase and its implication(s). Through iterative steps of analyses, comparisons, interpretations and reflection, we interpreted the dataset and in phase six concluded our research inquiry by drawing a preliminarily delineation of the term 'conceptualisation'. The philosophical framework that enriched our understanding in phase four was imperative for our delineation of the conceptualisation of a psychological measure. How we constructed psycho-philosophical lenses to view the conceptualisation of a psychological measure is pivotal and necessitates explanation.

\section{Inductive analysis as our psychological lens}

An inductive analysis of the generated dataset enabled us to condense the psychometric literature on the conceptualisation phase into a tabular format, to indicate how psychometric literature depicts this phase. As seen in Table 1, we documented 'activity-based captions' from the nine sources and preliminarily grouped these captions into pre-emptive, possible thematic relations. Probable synonyms, polysemy and equivalences were considered as another validation process to assure the themes and their captions carried the same meaning across literature. The grouped captions were categorised into themes and labelled according to the predominant trends and patterns of the captions. We present eight general themes with their 34 respective captions, as well as evidence of which authors' texts were analysed.

The majority of scholars included 'piloting the measure', determining the 'format of the test items', and the 'audience' as the most important aspects to consider when conceptualising a psychological measure. Some scholars alluded to the 'rationale' and 'construction, format and scaling of items' as important aspects also to consider in this phase. Yet, the smallest number of scholars included the role of the 'measure developer', elucidating and emphasising the 
TABLE 1: Psychometric and psychological literature pertaining to the 'conceptualisation phase'.

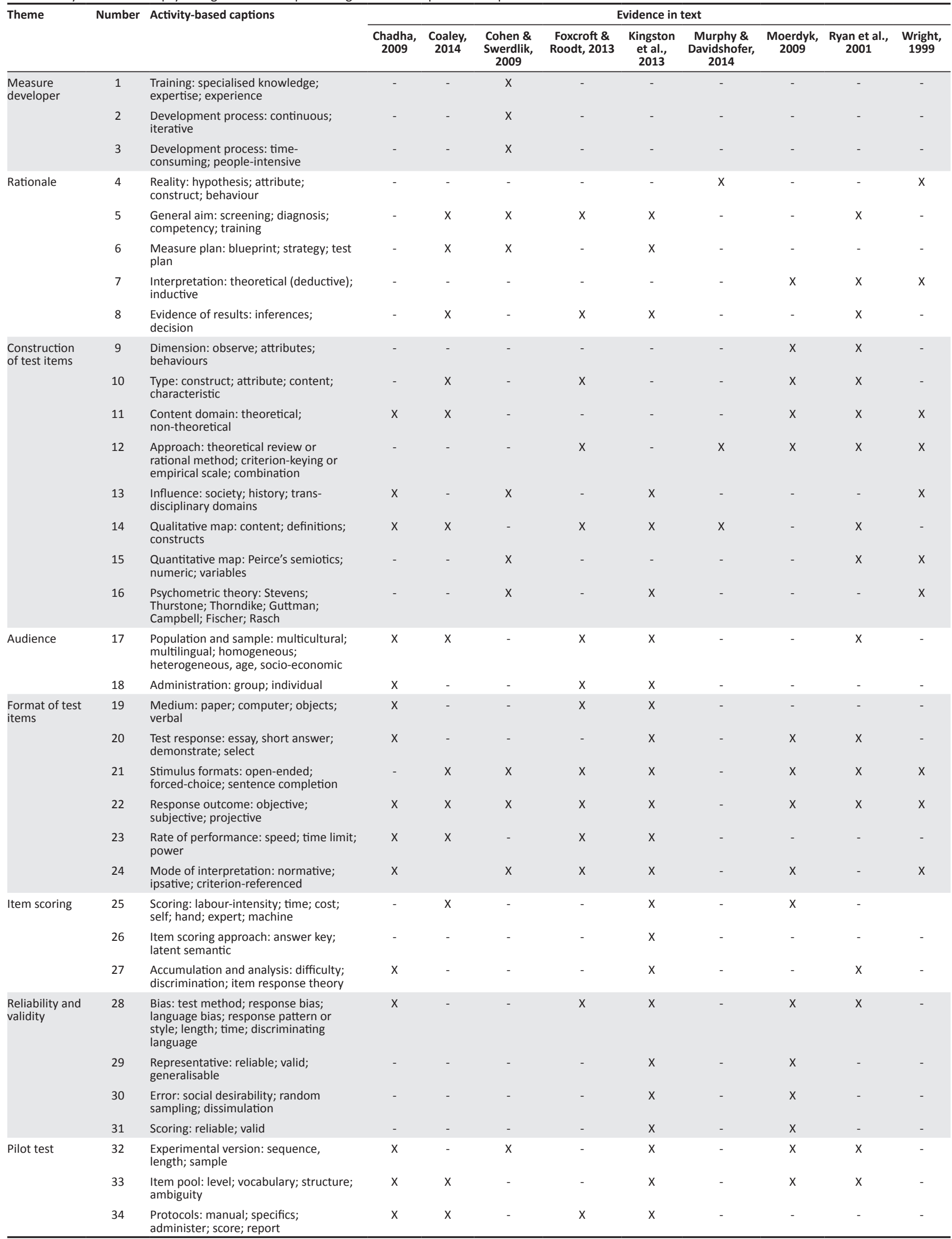

Note: Please see the full reference list of the article, Du Preez, H., \& De Klerk, W. (2019). A psycho-philosophical view on the 'conceptualisation' of psychological measure development. SA Journal of Industrial Psychology/SA Tydskrif vir Bedryfsielkunde, 45(0), a1593. https://doi.org/10.4102/sajip.v45i0.1593, for more information 
scope of practice of a serious measure developer. Looking at what was prevalently focused on in psychometric literature regarding the 'conceptualisation phase', it corroborates that psychological measures are rapidly operationalised and not sufficiently conceptualised. The 'type' (objective, subjective or projective), 'format' (open-ended, forced-choice or sentence completion) and 'description of constructs' are emphasised, while the 'knowledge, skills and dispositions' of the measure developer, as well as his or her theoretical framework, is almost entirely negated. It is assumed that serious measure developers are alike rather than unique, complex, individual and different. To illustrate the importance of considering the person who is utilising his or her social, emotional, cognitive, spiritual and physical views when developing a psychological measure, required that we analyse the same dataset deductively, using our philosophical framework.

\section{Deductive analysis as our psycho-philosophical lens}

The deductive analysis of the generated dataset enabled us to utilise the a priori framework to indicate a philosophical understanding of psychometric and psychological literature. We wanted to detect evidence of structured thought, experiences and rule-following activities that support a philosophical understanding of conceptualisation. By reanalysing the nine sources, we scrutinised the dataset for evidence of pre-scientific provisions in their descriptions of what constitutes the conceptualisation phase. Table 2 represents the process of deductive analysis.

The majority of these scholars incorporated transcendental, teleological and nomothetic positioning in their delineation of the conceptualisation phase, while the smallest number of

TABLE 2: Exploring philosophical provisions within psychometric literature pertaining to the 'conceptualisation phase'.

\begin{tabular}{|c|c|c|c|c|c|c|c|c|c|c|c|}
\hline \multirow[t]{2}{*}{ Theme } & \multirow[t]{2}{*}{ Number } & \multirow[t]{2}{*}{ Activity-based captions } & \multicolumn{9}{|c|}{ Evidence in text } \\
\hline & & & $\begin{array}{l}\text { Chadha, } \\
2009\end{array}$ & $\begin{array}{l}\text { Coaley, } \\
2014\end{array}$ & $\begin{array}{l}\text { Cohen \& } \\
\text { Swerdlik, } \\
2009\end{array}$ & $\begin{array}{l}\text { Foxcroft \& } \\
\text { Roodt, } 2013\end{array}$ & $\begin{array}{l}\text { Kingston } \\
\text { et al., } \\
2013\end{array}$ & $\begin{array}{c}\text { Murphy \& } \\
\text { Davidshofer, } \\
2014\end{array}$ & $\begin{array}{l}\text { Moerdyk, } \\
2009\end{array}$ & $\begin{array}{l}\text { Ryan et al., } \\
\quad 2001\end{array}$ & $\begin{array}{l}\text { Wright, } \\
1999\end{array}$ \\
\hline \multirow{4}{*}{$\begin{array}{l}\text { Integrated } \\
\text { personality } \\
\text { positioning }\end{array}$} & 1 & $\begin{array}{l}\text { Intentionally expresses his or her } \\
\text { ideological preferences }\end{array}$ & - & - & $x$ & - & - & - & - & - & - \\
\hline & 2 & $\begin{array}{l}\text { Intentionally expresses his or her } \\
\text { own socio-historical-cultural } \\
\text { predispositions and thinking }\end{array}$ & - & - & - & - & - & - & - & - & - \\
\hline & 3 & $\begin{array}{l}\text { Intentionally reflects on how to } \\
\text { unify ideological preferences } \\
\text { with measure development }\end{array}$ & - & - & - & - & - & - & - & - & - \\
\hline & 4 & $\begin{array}{l}\text { Research qualities (integrity, } \\
\text { moral reflectiveness, } \\
\text { authenticity, trustworthiness and } \\
\text { social responsiveness) }\end{array}$ & - & - & $\mathrm{x}$ & - & $\mathrm{x}$ & - & - & - & - \\
\hline \multirow[t]{5}{*}{$\begin{array}{l}\text { Transcendental } \\
\text { positioning }\end{array}$} & 5 & $\begin{array}{l}\text { Intentionally expresses his or her } \\
\text { theoretical deductions about the } \\
\text { scientific reality as constructs and } \\
\text { content }\end{array}$ & $x$ & $x$ & $x$ & $x$ & $x$ & $\mathrm{x}$ & - & $x$ & $x$ \\
\hline & 6 & $\begin{array}{l}\text { Intentionally expresses his or her } \\
\text { theoretical deductions about the } \\
\text { scientific method }\end{array}$ & $x$ & $x$ & $x$ & $x$ & $x$ & $\mathrm{x}$ & - & $\mathrm{x}$ & $x$ \\
\hline & 7 & $\begin{array}{l}\text { Intentionally reflects on his or } \\
\text { her choice to incorporate trans- } \\
\text { and cross-disciplinary knowledge } \\
\text { systems and the historicity of } \\
\text { measurement }\end{array}$ & - & - & - & $x$ & $x$ & - & - & $x$ & $x$ \\
\hline & 8 & $\begin{array}{l}\text { Intentionally expresses his or her } \\
\text { understanding of the meaning of } \\
\text { psychological behaviour and of } \\
\text { being in the world, or being } \\
\text { human }\end{array}$ & - & - & - & - & - & - & - & - & - \\
\hline & 9 & $\begin{array}{l}\text { Declares own assumptions, } \\
\text { values, predispositions and } \\
\text { intuitive thinking }\end{array}$ & - & - & $x$ & - & $x$ & - & - & - & - \\
\hline \multirow[t]{4}{*}{$\begin{array}{l}\text { Teleological } \\
\text { positioning }\end{array}$} & 10 & $\begin{array}{l}\text { Intentionally expresses the } \\
\text { outcome, purpose or aim of } \\
\text { measure }\end{array}$ & $x$ & $x$ & $x$ & $x$ & $x$ & $x$ & $x$ & $x$ & $x$ \\
\hline & 11 & $\begin{array}{l}\text { Intentionally reflects on the } \\
\text { repercussions or consequences } \\
\text { of the measurement }\end{array}$ & - & - & $x$ & $x$ & $x$ & - & - & - & - \\
\hline & 12 & $\begin{array}{l}\text { Intentionally reflects on the } \\
\text { continuous process of reflecting } \\
\text { and refining the measure }\end{array}$ & - & - & $x$ & $x$ & $x$ & - & - & - & - \\
\hline & 13 & $\begin{array}{l}\text { Intentionally reflects on the } \\
\text { trustworthiness and authenticity } \\
\text { of the measure }\end{array}$ & - & $x$ & $x$ & $x$ & $x$ & $x$ & - & $x$ & $x$ \\
\hline \multirow[t]{3}{*}{$\begin{array}{l}\text { Nomothetic } \\
\text { positioning }\end{array}$} & 14 & $\begin{array}{l}\text { Intentionally justifies audience } \\
\text { for whom measure is intended }\end{array}$ & $x$ & $x$ & $x$ & $x$ & $x$ & $x$ & $x$ & $x$ & $x$ \\
\hline & 15 & $\begin{array}{l}\text { Intentionally gives a justification } \\
\text { for scholars who are involved in } \\
\text { the measure development }\end{array}$ & - & - & $x$ & - & $x$ & - & - & - & - \\
\hline & 16 & $\begin{array}{l}\text { Intentionally reports on entire } \\
\text { development process (audit trail) }\end{array}$ & - & - & - & - & $x$ & - & - & - & - \\
\hline
\end{tabular}

Note: Please see the full reference list of the article, Du Preez, H., \& De Klerk, W. (2019). A psycho-philosophical view on the 'conceptualisation' of psychological measure development. SA Journal of Industrial Psychology/SA Tydskrif vir Bedryfsielkunde, 45(0), a1593. https://doi.org/10.4102/sajip.v45i0.1593, for more information. 
scholars assimilated the integrated personality positioning in their working definition. The most prevalent activity-based captions that were suggested are the 'intentional expression of his or her understanding of the outcome, purpose or aim of measure', 'trustworthiness of the measure' and the 'justification of audience' for whom the measure is intended. In contrast, the 'intentional expression of his or her own socio-historical-cultural predispositions and thinking and its influence on the measure development', and also 'his or her understanding of the meaning of psychological behaviour and of being in the world, or being human' were almost omitted.

\section{Limitations and recommendation}

We acknowledge the likelihood that more scientific sources, which fit the exact inclusion and exclusion criteria, may exist and this can be a limitation. Further identification of such sources for inductive and deductive analyses may result in the elimination or addition of themes and activity-based captions in ways that may further improve the trustworthiness of this inquiry. We are also aware that other philosophical frameworks could be utilised. Yet we are convinced that the content analysed from this sample was sufficient and we have reached inductive thematic saturation and a priori thematic saturation (Saunders et al., 2018). Interestingly, the small sample of analysed textual or typographical psychometric literature has shed light on the importance of utilising psycho-philosophical lenses to make sense of a scientific hiatus.

\section{Ethical consideration}

This research inquiry was approved and monitored by the Health Research Ethics Committee (HREC) and the NorthWest University Institutional Research Ethics Regulatory Committee (NWU-IRERC). Ethical clearance number: NWU00087-16-A1.

\section{Discussion and practical implications}

The most remarkable result to emerge from the data is that the conceptualisation phase merely expresses a synopsis on the agreement of what the scientific process entails, almost like an aerial view of the identified scientific reality and the applied scientific method. The transition from the conceptualisation phase of the scientific reality (ontology) and the scientific reality (epistemology) to the operationalisation phase of the measurement is swift, without considering the human positioning (anthropology and axiology) in the development of a psychological measure. Negating the human positioning in measure development is a serious lacuna. The proposed philosophical framework legitimises human reflexivity in the conceptualisation phase, which can enhance the integrity of the instrument. In our opinion, the four pre-scientific provisions can frame and inspire the delineation of the conceptualisation phase of a psychological measure in the following ways:

\section{Integrated personality positioning}

This can serve as a reminder that the serious measure developer should take a moment to become cognisant of himself or herself and take notice of self-interest as a possible motive (Comte-Sponville, 2005; Van der Walt \& Potgieter, 2012) before commencing the development of a psychological measure that could be worthwhile, useful and beneficial to others. An intentional opportunity for self-interest should challenge serious measure developers to reflect on their socio-historical and cultural predispositions about the phenomenon and the scientific method (Comte-Sponville, 2005; Van der Walt \& Potgieter, 2012). The reason for such an opportunity is that any scientific reality is socially, culturally, philosophically and historically constructed and affects how a theory of measurement and understanding is applied to develop a measure (Maul etal., 2016). Proper contextualisation of the scientific reality (ontology),the scientific method (epistemology) and the human positioning (anthropology and axiology) affects the entire development process (Finkelstein, 2003; Michell, 1997; Petocz \& Newbery, 2010).

\section{Transcendental positioning}

Conceptualisation should prompt serious measure developers to think about their ethical behaviour and morality (Harris, 2010; Van der Walt \& Potgieter, 2012), particularly because after following a set of methodological procedures (Maul et al., 2016; Petocz \& Newbery, 2010), a measure will be constructed and utilised by human beings. Opportunity should be created for serious measure developers to evaluate and reflect on their ideological and theoretical assumptions and their understanding of terminology and concepts in order to identify risks that could threaten the measure's internal and external structure, which could harm future test takers (Maul et al., 2016; Michell, 1997, 2005). The validity and reliability of the measure's structure is always of concern and require the measure developer to consider both the purpose and use of the measure (Coaley, 2014; Finkelstein, 2003). Although the diversity of ideology is acknowledged, certain shared systems of human understanding do exist, and its influence on how one views and applies a scientific phenomenon is accentuated (Burgess \& Plunkett, 2013; Michell, 1997, 2005). The measure developer's own anthropological positioning and approach to developing such a measure is an intrinsic and important part of the process (Michell, 1997, 2005; Petocz \& Newbery, 2010) and proper conceptualisation can help measure developers move beyond an epistemological focus and achieve an ontological essence (Maul et al., 2016; Petocz \& Newbery, 2010).

\section{Teleological positioning}

Along with the intentional act of reflecting on and explaining the purpose of the measure, to ensure that the internal and external structure contributes towards the aim (Coaley, 2014), the conceptualisation phase should also consider the individual for whom the measure is intended. The continuous and conscious engagement of scholars to construct, change, 
create, define, develop, give, interpret, justify, make and/or rationalise the use and applicability of a measure is an important practice (Babbie \& Mouton, 2001; Van der Walt \& Potgieter, 2012). No measure is faultless or perpetually relevant and should be revisited and adapted and, in some sense, reconceptualised. The validity and reliability of the measure rely on the continuous involvement of measure developers throughout the entire development process and on their collaboration with scholars to attain the purpose of the envisioned measure in an ethical and moral way (Michell, 1997, 2005; Petocz \& Newbery, 2010).

\section{Nomothetic positioning}

The conceptualisation phase also necessitates that not only should the serious measure developer consider the audience for whom the measure is intended, but they should also establish beforehand their collaborating measure development team. Each human participant introduces his or her own integrated personality, as well as their transcendental and teleological orientation to the development process (Delanty \& Strydom, 2010; Van der Walt \& Potgieter, 2012). The latter is a crucial element to introduce multiple views and to expand our use of language pertaining to the scientific reality and scientific method. The conceptualisation phase creates the opportunity to co-construct a clear conceptual vocabulary by collaborating for meaning on the scientific reality, as well as the scientific method (Humphry, 2013; Maul et al., 2016). The engagement of the measure developer with the conceptualisation and with all the operational phases justifies that they can coexist (Petocz \& Newbery, 2010) and, in turn, promote the outcomes and trustworthiness of the measure that will serve humankind.

\section{Conclusion and recommendations}

To introduce a philosophical stance when conceptualising a psychological measure gives the serious measure developer the edge to obtain a clearer view of the scientific reality and the scientific method throughout the entire process:

The greater the field of our awareness and understanding, the more we can transform from mute followers of rigid authoritarian prescriptions into authentic and willing embracers of aporia and enlightened ignorance. (Petocz \& Newbery, 2010, p. 141)

On the other hand, overlooking the fundamental role of the philosophical framework during the conceptualisation of a psychological measurement can have serious repercussions for test developers and the test users. The conceptualisation of a psychological measure calls for a serious measure developer, who intentionally shows awareness of the intricate relationship that exists between language and thinking, as well as the social, cultural and historical nature of infused scientific knowledge systems about reality, method and being. The serious measure developer should furthermore intentionally reflect on their own structure of thought, experiences, rule-following, cognitive and linguistic capacities about the scientific reality, scientific method and being, as the meaning and understanding of the latter are loaded with socio-contemporaneity and socio-linguistic interpretations. A serious measure developer should justify and clearly express their understanding of conceptualisation in a well-defined theory in a mathematical and linguistic language. We are of the opinion that utilising the proposed psycho-philosophical lens can herald further studies that promote the rootedness of any type of theoretical framework in those philosophical principles that influence serious measure developers' understanding and measurement of a psychological phenomenon.

\section{Acknowledgements}

This article is based on the MA mini-dissertation of $\mathrm{H}$. Du Preez, entitled, 'A conceptual analysis of conceptualisation as first phase in the development of a psychological measurement', under the supervision of W. de Klerk, NorthWest University, Potchefstroom.

\section{Competing interests}

The authors declare that they have no financial or personal relationships that may have inappropriately influenced them in writing this article.

\section{Author's contributions}

H.D.P. is the lead author and responsible for conducting the entire research inquiry. H.D.P. and W.d.K. collaborated in conceptualising and designing the research inquiry. H.D.P. continuously scanned, scoped, gathered and selected the most suitable textual sources for analysis and interpretation in a systematic and purposive manner. W.d.K. is the co-author and supervisor of this article and was responsible for the critical reading, synthesis and analysis of all content in the manuscript.

\section{Funding}

This research received no specific grant from any funding agency in the public, commercial, or not-for-profit sectors.

\section{Data availability statement}

Data sharing is not applicable to this article as no new data were created or analysed in this study.

\section{Disclaimer}

The authors confirm that this work is original and has not been published elsewhere, nor is it currently under consideration for publication elsewhere. Furthermore, they also confirm that the content represented in this article is their own and not an official position of the institution or funder.

\section{References}

Anastasi, A., \& Urbina, S. (1997). Psychological testing (7th edn.). New York: PrenticeHall International.

Babbie, E., \& Mouton, J. (2001). The practice of social research. Cape Town, South Africa: Oxford University Press. 
Bond, T. G., \& Fox, C. M. (2015). Applying the Rasch Model: Fundamental measurement in the human sciences (3rd edn.). New York: Routledge.

Boone, W. J., Staver, J. R., \& Yale, M. S. (2014). Rasch analysis in the human sciences. Dordrecht: Springer

Borsboom, D. (2005). Measuring the mind: Conceptual issues in contemporary psychometrics. Cambridge, UK: Cambridge University Press.

Borsboom, D. (2006). The attack of the psychometricians. Psychometrika, 71(3), 425-440. https://doi.org/10.1007/s11336-006-1447-6

Burgess, A., \& Plunkett, D. (2013). Conceptual ethics I. Philosophy Compass, 8(12), 1091-1101. https://doi.org/10.1111/phc3.12086

Chadha, N. K. (2009). Test construction. New York: Sage.

Coaley, K. (2014). An introduction to psychological assessment and psychometrics. London, UK: Sage.

Cocchiarella, N. B. (2007). Formal ontology and conceptual realism (Vol. 339) Amsterdam, The Netherlands: Springer.

Cohen, J. C., \& Swerdlik, M. E. (2009). Psychological testing and assessment: An introduction to tests and measurement(7th edn.). London, UK: McGraw-Hill.

Comte-Sponville, A. (2005). The little book of philosophy. London, England: Vintage Random House.

Delanty, G., \& Strydom, P. (2010). Philosophies of social science: The classic and contemporary readings. Philadelphia, PA: Open University Press.

De Vos, A. S., \& Strydom, H. (2011). Scientific theory and professional research In A. S. De Vos, H. Strydom, C. B. Fouché, \& C. S. L. Delport (Eds.), Research at grassroots. For the social sciences and human service professions (4th edn. pp. 28-44). Pretoria, South Africa: Van Schaik.

Drake, S. (1999). Essays on Galileo and the history and philosophy of science (Vol. 1) Toronto: University of Toronto Press.

Finkelstein, L. (2003). Widely, strongly and weakly defined measurement. Measurement, 34(1), 39-48. https://doi.org/10.1016/S0263-2241(03)00018-6

Foxcroft, C., \& Roodt, G. (2013). An introduction to psychological assessment in the South African context (4th edn.). Cape Town, South Africa: Oxford University Press.

Goldstein, G., \& Beers, S. (Eds.). (2004). Comprehensive handbook of psychological assessment (Vol. I). Hoboken, NJ: John Wiley.

Guarino, N. (1995). Formal ontology, conceptual analysis and knowledge representation. International Journal of Human-Computer Studies, 43(5), 625-640. https://doi.org/10.1006/ijhc.1995.1066

Hacker, P. M. S. (2013). Prologue: Wittgenstein's philosophy of psychology as a critical instrument for the psychological sciences. In T. P. Racine \& K. L. Slaney (Eds.) A Wittgensteinian perspective on the use of conceptual analysis in psychology (pp. 10-27). Hampshire, UK: Palgrave Macmillan.

Harris, S. (2010). The moral landscape. How science can determine human values. London, England: Bantam.

Hughes, M., \& Duffy, C. (2018). Public involvement in health and social sciences research: A concept analysis. Health Expectations, 21(6), 1183-1190. https://doi. org/10.1111/hex.12825

Humphry, S. M. (2013). Understanding measurement in light of its origins. Frontiers in Psychology, 4(113), 1-8. https://doi.org/10.3389/fpsyg.2013.00113

Hutto, D. (2013). Psychology's inescapable need for conceptual clarification. In T. P. Racine \& K. L. Slaney (Eds.), A Wittgensteinian perspective on the use of conceptual analysis in psychology (pp. 28-50). Hampshire, UK: Palgrave Macmillan.
Jones, L. V., \& Thissen, D. (2006). A history and overview of psychometrics. Handbook of Statistics, 26(2006), 1-27. https://doi.org/10.1016/S0169-7161(06)26001-2

Kingston, N. M., Scheuring, S. T., \& Kramer, L. B. (2013). Test development strategies. In K. F. Geisinger (Ed.), APA handbook of testing and assessment in psychology (Vol. 1, pp. 165-184). Washington, DC: American Psychological Association.

Margolis, E., \& Laurence, S. (2007). The ontology of concepts - Abstract objects or mental representations? Noûs, 41(4), 561-593. https://doi.org/10.1111/j.14680068.2007.00663.x

Maul, A. (2013). On the ontology of psychological attributes. Theory \& Psychology, 23(6), 752-769. https://doi.org/10.1177/0959354313506273

Maul, A., Torres Irribarra, D., \& Wilson, M. (2016). On the philosophical foundations of psychological measurement. Measurement, 79(February), 311-320. https://doi. org/10.1016/j.measurement.2015.11.001

Michell, J. (1997). Quantitative science and the definition of measurement in psychology. British Journal of Psychology, 88(3), 355-383. https://doi.org/ 10.1111/j.2044-8295.1997.tb02641.x

Michell, J. (2005). The logic of measurement: A realist overview. Measurement, 38(4) 285-294. https://doi.org/10.1016/j.measurement.2005.09.004

Moerdyk, A. (2009). The principles and practice of psychological assessment. Pretoria, South Africa: Van Schaik.

Murphy, K. R., \& Davidshofer, C. O. (2014). Psychological testing: Principles and applications (6th edn.). Upper Saddle River, NJ: Pearson Education.

Nuopponen, A. (2010a). Method of concept analysis - A comparative study. Part 1 of 3. LSP Journal, 1(1), 4-12.

Nuopponen, A. (2010b). Methods of concept analysis - Towards systematic concept analysis. Part 2 of 3. LSP Journal, 1(2), 5-14.

Nuopponen, A. (2011). Methods of concept analysis - Tools for systematic concept analysis. Part 3 of 3. LSP Journal, 2(1), 4-15.

Oono, Y. (2012). The nonlinear world: Conceptual analysis and phenomenology. New York: Springer Science \& Business Media.

Petocz, A., \& Newbery, G. (2010). On conceptual analysis as the primary qualitative approach to statistics education research in psychology. Statistics Education Research Journal, 9(2), 123-145.

Ryan, J. J., Lopez, S. J., \& Sumerall, S. W. (2001). Understanding test construction. In W. I. Dorfman \& M. Hersen (Eds.), Understanding psychological assessment (pp. 1-15). New York: Kluwer Academic.

Saunders, B., Sim, J., Kingston, T., Baker, S., Waterfield, J., Bartlam, B., ... Jinks, C. (2018). Saturation in qualitative research: Exploring its conceptualization and operationalization. Quality \& Quantity, 52(4), 1893-1907. https://doi.org/ 10.1007/s11135-017-0574-8

Schweizer, K., \& DiStefano, C. (Eds.). (2016). Principles and methods of test construction. Standards and recent advances (Vol. III). Boston, MA: Hogrefe.

Tranfield, D., Denyer, D., \& Smart, P. (2003). Towards a methodology for developing evidence-informed management knowledge by means of systematic review. British Journal of Management, 14(3), 207-222. https://doi.org/10.1111/14678551.00375

Van der Walt, J. L., \& Potgieter, F. J. (2012). Research method in education: The frame by which the picture hangs. International Journal of Multiple Research Approaches, 6(3), 220-232. https://doi.org/10.5172/mra.2012.6.3.220

Wright, B. D. (1999). Fundamental measurement for psychology. In S. E. Embretson \& S. L. Hershberger (Eds.), The new rules of measurement (pp. 65-104). Mahwah, NJ: Lawrence Erlbaum. 